\title{
Green House Effect vs. Infrared Radiation Emissions
}

Ben Slama $\mathbf{R}^{*}$

ISSAT Gabes, University of Gabes, Road of Medenine, Tunisia

*Corresponding author: Ben Slama R, ISSAT Gabes, University of Gabes, Road of Medenine, Tunisia, Tel: (+216)75 396 955; E-mail: Benslama_romdhane@yahoo.fr

Received date: Mar 02, 2016; Accepted date: Apr 15, 2016; Published date: Apr 22, 2016

Copyright: () 2016 Slama RB. This is an open-access article distributed under the terms of the Creative Commons Attribution License, which permits unrestricted use, distribution, and reproduction in any medium, provided the original author and source are credited.

\begin{abstract}
Emissions of greenhouse gas GHGs, such as $\mathrm{CO}_{2}$ and its equivalents, induce global warming of the earth. This article is highlighted, and recalled, that these GHGs are selective about the radiation reaching them. Solar radiation, whose the spectrum ranges from UV to near IR through them. By against the far-infrared stopped. Thus, it is necessary to warn about the surfaces that emit in the far-infrared spectrum, arrested by the GHGs. These surfaces are either natural, in which case they are part of the ecosystem, and that's natural, or they are buildings built by man, whose dark surfaces made artificially, by contemporary man, causing the absorption of solar radiation on the day and emitting, after heating, in the far infrared spectrum. Humanity must therefore limit the proliferation of dark surfaces, through for example, buildings coatings, roads and Highways, vehicles, and even our clothes. Do not underestimate them in the IR emissions to the earth's atmosphere and retained by GHGs, causing the heating of the earth and climate change. Indeed, it takes very little to disrupt the ecosystem as with any system in equilibrium.
\end{abstract}

Keywords: Global warming; Greenhouse effect; Infrared radiation; Emittance; Dark colour

\section{Introduction}

Worldwide, it is in favour of reducing GHG emissions. It's good. But what do these GHGs? They reflect terrestrial radiation to the earth itself, where warming due to the imprisonment of such radiation. But what are these far infrared radiations IR type. So, should we not also be acting not only on the reducing GHG emissions, but also at least as much about the origin of the IR radiation surfaces emitting. Where do these radiations? They are in fact produced by the earth surfaces following two ways: first, the fact that the surface of the earth is hotter than the atmosphere, there is an emission of far infrared radiation; the latter occurs only on the day when the earth's surface illuminated by the sun, absorbing a part of the solar radiation whose spectrum ranges from 0.25 to $2.5 \mu \mathrm{m}$ while the radiation from the Earth's surface have wavelength larger and are in the far infrared area.

Which colours of surfaces produce the IR from solar radiation: only dark-colored surfaces, such as roads, pavements, building coatings, vehicle bodies, and even our clothes all these visible surfaces absorb sunlight and convert it into far IR, which is then trapped by greenhouse gases. As for the white or light colours, they absorb only very little solar radiation, and therefore reflecting it and not heat up very little, and consequently their emittance in the IR spectrum, remains low.

Thus, it seems therefore that the warming due to greenhouse effect is caused by the simultaneous combination of two phenomena: GHGs themselves and land IR radiation that reach them. So action to limit greenhouse gas production, that's a good initiative, however there is no action, for the moment, on the reduction and limitation of dark surfaces that convert solar radiation into IR. A new research field is therefore open to the same extent as the importance of protecting the earth by greenhouse gas reduction from their origins.
The present paper is a reflection on the well-known greenhouse effect due to greenhouse gas emissions. An extension of the reflection was oriented to the type of radiation trapped by the greenhouse gases and especially the land on surfaces that issue. Obviously it is the dark surfaces, black in particular; who, during the day, absorb solar radiation and re-emit some infrared, far type, which only is stopped by the GHG inducing global warming.

\section{Bibliographical Study}

Many authors mention the link between the infrared radiations emitted by internal or external surfaces of buildings [1]. Others authors cite the close link between received and emitted radiation by land $[2,3]$ and global warming [4] (Figure 1).

Indeed, the atmosphere, oceans and continents of the surface absorb solar radiation (short wavelengths: 0.2 to $4 \mu \mathrm{m}$ ). This has the effect of increasing their temperature or at least maintains their balance. Now everybody brought to a certain temperature in turn emits radiation. The wavelength of the radiation depends on the temperature of the emitting surface. Thus, the earth (surface and atmosphere) emits infrared radiation (between 5 and $100 \mu$ ). This radiation is emitted towards the space $[5,6]$ and represents a loss of energy for the Earth. The overall balance is zero. However in the presence of greenhouse gases, this far IR is not transmitted into space and thus reflected towards the earth causing its warming, which climate changes that humanity is well aware.

The infrared radiation of the Earth can be measured by satellites equipped with sensors sensitive to this radiation and redirected toward Earth. The image of Figure 2 represents an average of the measurements performed during the month of March 2001. 
Citation: Ben Slama R (2016) Green House Effect vs. Infrared Radiation Emissions. J Climatol Weather Forecasting 4: 161. doi: $10.4172 / 2332-2594.1000161$

Page 2 of 5

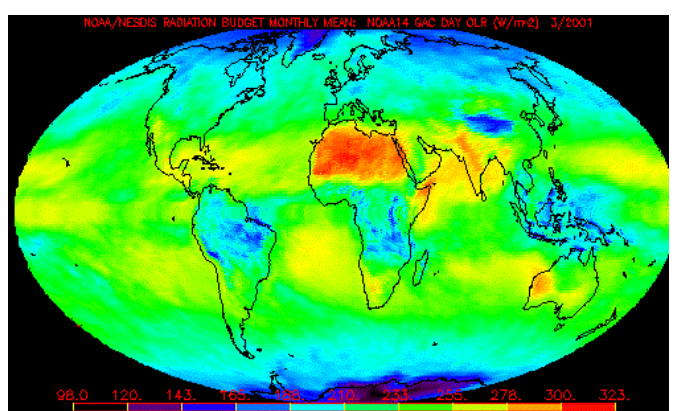

Figure 1: Emitted IR radiation by the earth [3].

\section{Analogy between the Solar Collector and Our Planet Earth}

Being myself a specialist in solar energy, thermal conversion, and to understand the purpose of this article, it is clear to begin with a reminder of the thermal captation of the solar radiation, in which I think there is a similarity with the theme treated here since both are concerned with the greenhouse effect, but one favorable and one unfavorable.

The principle of solar collectors is well known. It consists of an absorber (black), a window (to create the greenhouse effect, and cause the absorber warming), and thermal insulation to retain heat (Figure 2).

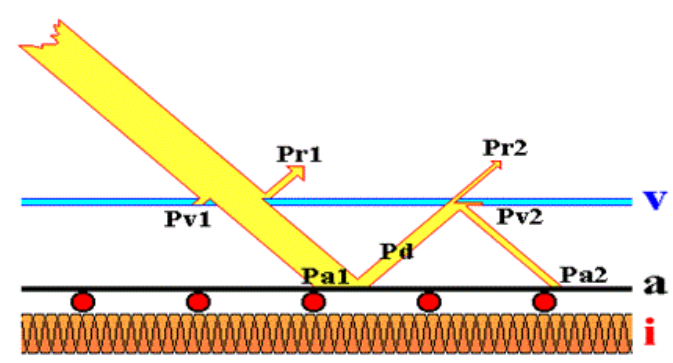

Figure 2: Constitution of a solar collector. V=Glazing. A=Absorber. $\mathrm{I}=$ Thermal insulation. Creation of the greenhouse effect.

During operation, it is necessary to place a glazing that lets the solar spectrum and which reflects thereafter the infrared emitted by the absorber; moreover black; that is how the far IR is product.

Cons example: Imagine now if the absorber is white, so it will directly reflect incoming solar radiation which will be possible to pass through the selective glazing; so there will be no heating in the collector!

By analogy, these observations of the phenomenon of the greenhouse effect throughout the solar collector can be extrapolated across the planet earth on receipt of solar radiation and warming by greenhouse gases.

Figure 3 illustrates this phenomenon: solar radiation transmission and reflection of infrared radiation.

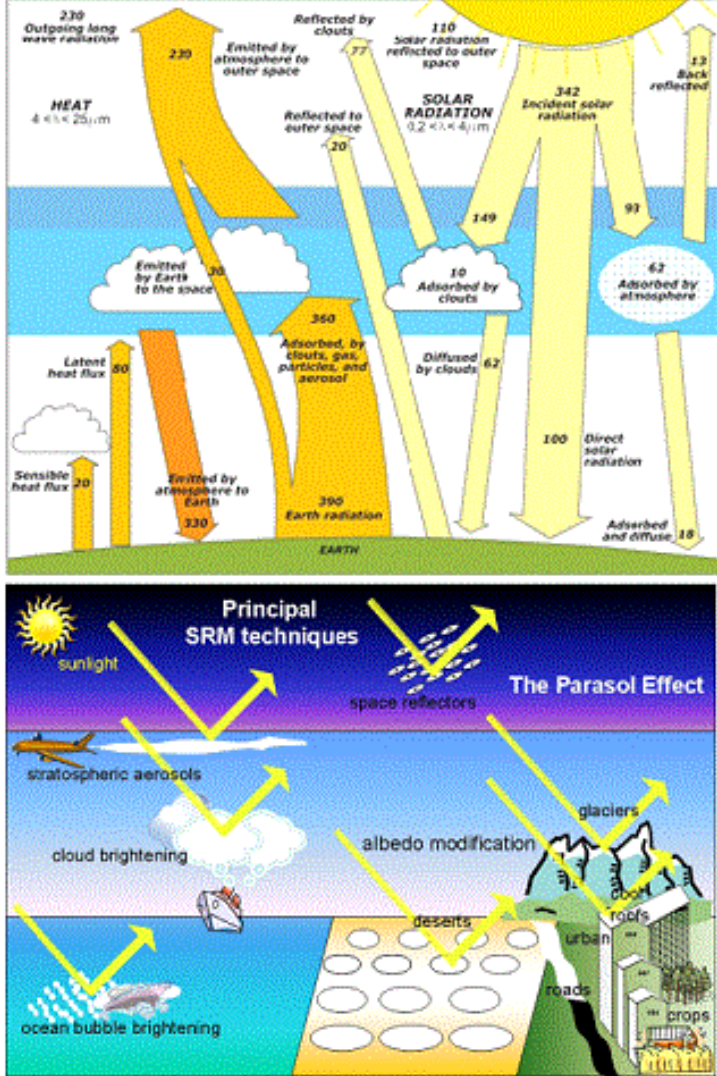

Figure 3: The earth, sun, IR emissions and albedo modification [7, 8].

\section{Another Natural Finding}

The formation of the rainbow with its different colours, this distinction as the red outer side of the bow and blue inner side, proves that large radiation wavelength, such as infrared are reflected by the atmosphere while the low wavelength radiation such as blue arrive to cross it (Figure 4).

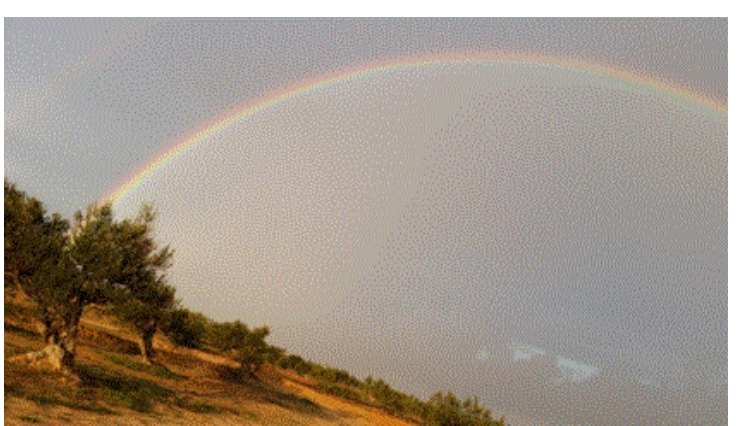

Figure 4: Photo of the rainbow.

To show that the gas stop much a part of the solar spectrum, like a window, we have the following experience: by the fire and in the 
Citation: Ben Slama R (2016) Green House Effect vs. Infrared Radiation Emissions. J Climatol Weather Forecasting 4: 161. doi:

Page 3 of 5

presence of sunlight, is well observed that the flame and smoke have a shadow even mild compared to that of trees.

Furthermore, glazing has also a shadow, albeit slightly visible, but shows that solar radiation is partly stopped: it is the greenhouse effect. Other experience: when a local window is partially exposed to the sun, we see that the lower part exposed to the sun heats, while the upper part remains cold (Figure 5).

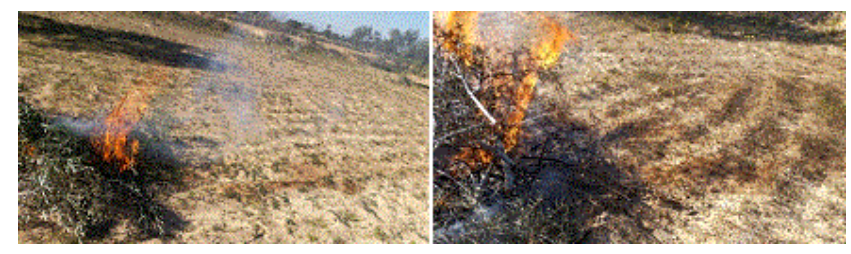

Figure 5: Photo of the wood fire shadow and the smoke.

Naturally, the earth sending its heat day and night by radiation, but also the day in the presence of the sun, occurs an increase of IR emissions.

The atmosphere consists of gases (nitrogen, oxygen, argon, water vapor, etc.), including $\mathrm{CO}_{2}$ passes solar radiation, including near infrared.

By intercepting the earth's surface, solar radiation is either:

- Reflects by areas of clear colour, like the moon, and this radiation could well back across the Earth's atmosphere toward the universe.

- Fully absorbed by dark surfaces and especially black as roadways, dark exterior cladding of buildings, and even the black clothes of individuals. After absorption, these surfaces will in turn emit radiation located in the far infrared. Its average wavelength is given by the law of Vien:

$\lambda_{\text {moy }}=2898 /$ T Temperature in Kelvin.

The spectrum of electromagnetic radiation is between 0.5 and 5 times $\lambda_{\text {moy, }}$

In the case of the sun, the temperature is taken to be $6000 \mathrm{~K}$, so $\lambda_{\text {moy }}=0.5 \mu \mathrm{m}$.

The spectrum of the radiation is in the range of $0.25 \mu \mathrm{m}$ and $2.5 \mu \mathrm{m}$.

However, for the planet earth heated during the day by the sun, as a solar collector, the temperature can be approximated to $50^{\circ} \mathrm{C}$, so a mean wavelength of $8.97 \mu$ and a spectrum between 4.48 and $44.86 \mu$. This cannot pass through the atmosphere, especially polluted. During the night, with lower temperatures of the earth, the spectrum is shifted to even more distant values in the infrared.

\section{Impact of Artificial Elements on IR Emissions and Global Warming}

During the day, in the presence of sunlight a clear sky, at the earth's radiation emissions in the IR spectrum to the atmosphere, is added the infrared radiation emitted by artificial structures such as roads, cities and even individuals that emit in the same order of magnitude of the wavelength perspective; This is the very purpose of this discussion and the writing of this article. Obviously this only applies to the daytime radiation surplus due to the artificial elements that absorb solar radiation (Figures 6-8).

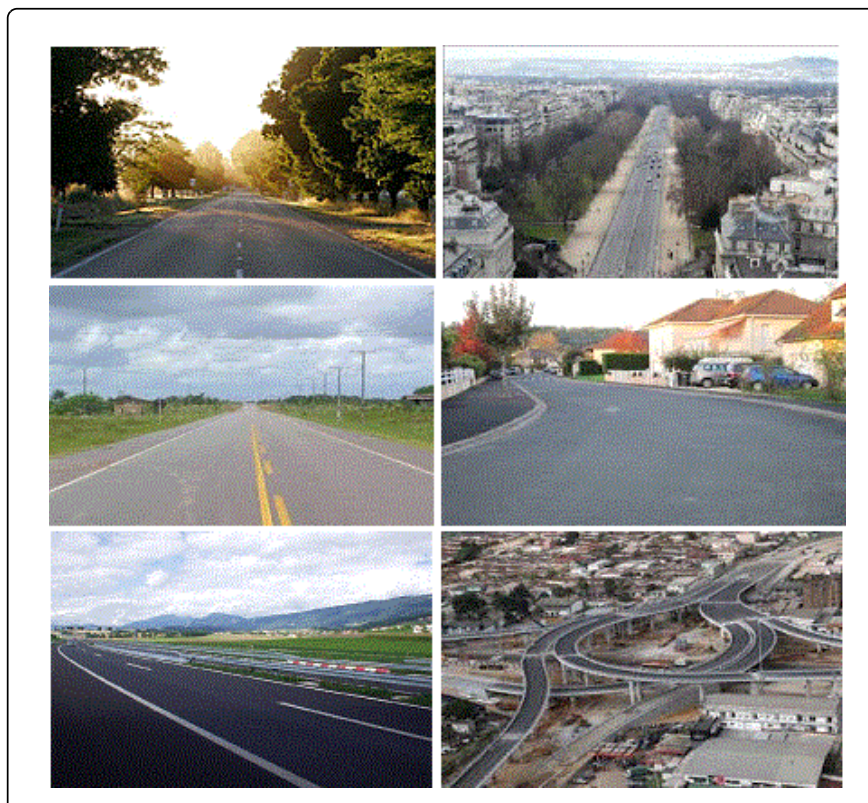

Figure 6: The dark colours of roads and pavements and the IR emissions.
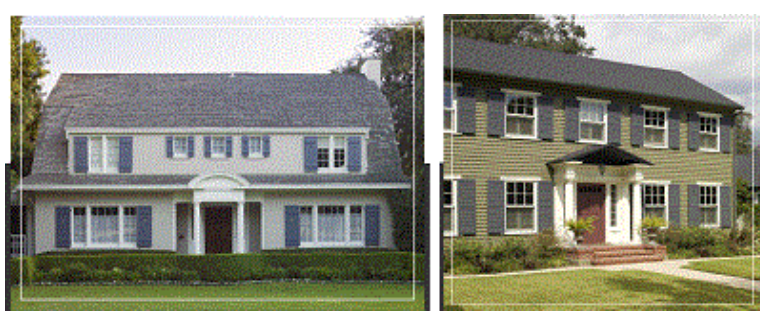

Figure 7: The dark colours of buildings and the emissions IR.

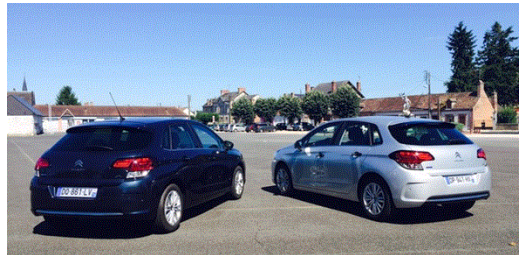

Figure 8: The dark colours of vehicles and the emissions IR.

Thus, the $\mathrm{CO}_{2}$ acts as a greenhouse effect gas if it is opposed to the infrared radiation emitted from the surface of the earth, at the crossing and penetration of the atmosphere in a natural way. This IR radiation is far type. Are added to this radiation, the IR emission of so hot and dark surfaces of artificial structures, built by man on earth. It is therefore urgent to limit the size of the emitting surfaces and prevent their expansion (Table 1).

The emitted power by a matte surface, heated by the sun and depending on its temperature is given by: 
Citation: Ben Slama R (2016) Green House Effect vs. Infrared Radiation Emissions. J Climatol Weather Forecasting 4: 161. doi:

Page 4 of 5

And the corresponding mean wavelength is given by: $\lambda_{\text {men }}$

\begin{tabular}{|l|l|l|l|l|l|l|}
\hline $\begin{array}{l}\text { Temperature of the } \\
\text { surface }\end{array}$ & $20^{\circ} \mathrm{C}$ & $30^{\circ} \mathrm{C}$ & $40^{\circ} \mathrm{C}$ & $50^{\circ} \mathrm{C}$ & $60^{\circ} \mathrm{C}$ & $70^{\circ} \mathrm{C}$ \\
\hline $\begin{array}{l}\text { average wavelength of } \\
\text { the radiation }\end{array}$ & 9.89 & 9.56 & 9.25 & 8.97 & 8.70 & 8.44 \\
\hline $\begin{array}{l}\text { Power of radiation } \\
\text { causing the greenhouse } \\
\text { effect }\left(\mathrm{W} / \mathrm{m}^{2}\right)\end{array}$ & 417 & 478 & 544 & 617 & 697 & 785 \\
\hline
\end{tabular}

Table 1: Emitted power by a matte surface.

It should be noted that the power emitted at $70^{\circ} \mathrm{C}$ is almost twice that at low temperature $\left(20^{\circ} \mathrm{C}\right)$. Thus, should be to prevent the surfaces heat up under the effect of the sun. However, the sun cannot be easily avoided. By cons, it is possible to prevent its absorption by the use of clear and not dark surfaces. Indeed, the absorption coefficient of solar radiation by a surface depends on its colour, as shown in (Table 2).

\begin{tabular}{|l|l|}
\hline $\begin{array}{l}\text { Surface Colour } \\
\text { (approximated) }\end{array}$ & $\begin{array}{l}\text { Absorb Factor - Fraction of Incident Radiation } \\
\text { Absorbed }\end{array}$ \\
\hline $\begin{array}{l}\text { White smooth } \\
\text { surfaces }\end{array}$ & $0.25-0.40$ \\
\hline Grey to dark grey & $0.40-0.50$ \\
\hline Green, red and brown & $0.50-0.70$ \\
\hline Dark brown to blue & $0.70-0.80$ \\
\hline Dark blue to black & $0.80-0.90$ \\
\hline
\end{tabular}

Table 2: Influence of surfaces colour on the absorption coefficient of solar radiation.

The type of material also influences the absorption coefficient of solar radiation (Table 3 ).

\begin{tabular}{|l|l|}
\hline Substance & $\begin{array}{l}\text { Absorb Factor - Fraction } \\
\text { of Incident Radiation } \\
\text { Absorbed }\end{array}$ \\
\hline Aluminum, polished & 0.3 \\
\hline Aluminum paint & 0.2 \\
\hline Aluminum, anodized & 0.15 \\
\hline Brick, glazed & 0.35 \\
\hline Brick, common light red & 0.55 \\
\hline Brick, common red & 0.68 \\
\hline Brick, wire cut red & 0.52 \\
\hline Brick, blue & 0.89 \\
\hline Cork & 0.45 \\
\hline Limestone, light & 0.35 \\
\hline Limestone, dark & 0.5 \\
\hline Linoleum, red-brown & 0.84 \\
\hline Sandstone, light grey & 0.62 \\
\hline
\end{tabular}

\begin{tabular}{|c|c|}
\hline Sandstone, red & 0.73 \\
\hline Marble, white & 0.44 \\
\hline Soft rubber, gray & 0.65 \\
\hline Marble, dark & 0.66 \\
\hline Granite, reddish & 0.55 \\
\hline Magnesium oxide, evaporated & 0.08 \\
\hline Graphite & 0.84 \\
\hline Porcelain & 0.5 \\
\hline Steel, vitreous enameled green & 0.76 \\
\hline Steel, vitreous enameled dark red & 0.81 \\
\hline Steel, vitreous enameled blue & 0.8 \\
\hline Iron, galvanized new & 0.64 \\
\hline Iron, galvanized dirty & 0.92 \\
\hline Iron, galvanized white washed & 0.22 \\
\hline Concrete & 0.6 \\
\hline Copper, polished & 0.18 \\
\hline Copper, tarnished & 0.64 \\
\hline Lead, old & 0.79 \\
\hline Asbestos cement, roof tiles old & 0.83 \\
\hline Asbestos cement, roof tiles red & 0.69 \\
\hline Asbestos slate & 0.81 \\
\hline Asphalt roofing, new & 0.91 \\
\hline Asphalt roofing, old & 0.82 \\
\hline Bitumen-covered roofing sheet, brown & 0.87 \\
\hline Slate, blue grey & 0.87 \\
\hline Tile, clay red & 0.64 \\
\hline Tile, concrete uncolored & 0.65 \\
\hline Tile, concrete black & 0.91 \\
\hline Vitreous enamel, white & 0.39 \\
\hline White Dutch tile & 0.18 \\
\hline
\end{tabular}

Table 3: Absorbed solar radiation by material.

In addition, the surface heating due to the absorption of solar radiation and colour according to their armature.

- create significant temperature differences

- cause premature aging finishes

- cause blistering (if significant moisture wood)

- cause flaking

- promote resin flow 
Citation: Ben Slama R (2016) Green House Effect vs. Infrared Radiation Emissions. J Climatol Weather Forecasting 4: 161. doi: $10.4172 / 2332-2594.1000161$

Page 5 of 5

- favour the dimensional changes

\section{Conclusion}

The thermal balance of the ecological system of the earth has always includes the infrared emission to the atmosphere and warming by the greenhouse effect. As a balance "Roberval" the imbalance is quickly achieved simply by adding a small amount (epsilon) IR radiation emission.

The infrared emitted by artificial structures created by man, after absorption of solar radiation, albeit low in proportion, but enough to affect the ecological balance. The action to be taken here is to avoid the proliferation of dark surfaces that absorb fully solar radiation and then emit in the IR. Otherwise, the light colours reflect sunlight that can always cross back easily the atmosphere, unlike infrared.

The infrared radiation emitted by artificial structures created by man, after absorption of solar radiation, albeit low in proportion, but enough to affect the ecological balance. The action to be taken is to avoid the proliferation of dark surfaces that absorb fully solar radiation and then emit in the IR. Otherwise light colours reflect sunlight which can always cross back easily the atmosphere unlike infrared.

\section{References}

1. Szargut JT (2003) Anthropogenic and natural exergy losses (exergy balance of the Earth's surface and atmosphere). Energy 28: 1047-1054.

2. Petit M (2003) The greenhouse effect, impacts and possible solutions: overall credibility? C R Geoscience 335: 497-501.

3. http://eduscol.education.fr/obter/appliped/climat/pistpeda/bilanrad/ bilan5.htm

4. Knox RS (1999) Physical aspects of the greenhouse effect and global warming. American Journal of Physics 67: 1227.

5. Kokkila SI, Bera PP, Francisco JS, Lee TJ (2012) A group increment scheme for infrared absorption intensities of greenhouse gases. Journal of Molecular Structure 1009: 89-95.

6. http://www.notre-planete.info/actualites/ actu_2695_spectrophotometrie_infrarouge_effet_serre.php

7. http://planet-terre.ens-lyon.fr/article/bilan-radiatif-terre3.xml

8. Ming T, de_Richter R, Liu W, Caillol S (2014) Fighting global warming by climate engineering: Is the Earth radiation management and the solar radiation management any option for fighting climate change? Renewable and Sustainable Energy Reviews 31: 792-834. 